\title{
OS ARTEFACTOS LÍTICOS TALHADOS DO LITORAL DE VILA NOVA DE GAIA: CARACTERIZAÇÃO GENÉRICA, CONTEXTUALIZAÇÃO GEOARQUEOLÓGICA, PROBLEMAS E PERSPECTIVAS
}

\author{
SÉRGIO MONTEIRO-RODRIGUES ${ }^{(1)}$, ALBERTO GOMES $^{(2)} \&$ JOÃO PEDRO CUNHA-RIBEIRO ${ }^{(3)}$
}

Resumo:

Abstract:

\author{
O litoral de Vila Nova de Gaia, a sul da cidade do Porto, constitui um trecho geoarqueológico ímpar para o estudo da \\ ocupação quaternária da fachada ocidental da Ibéria. Neste trabalho apresentam-se algumas características tecno- \\ tipológicas das indústrias líticas do litoral de Vila Nova de Gaia e avançam-se hipóteses sobre os respetivos contextos \\ cronoestratigráficos, litoestratigrágicos e geoarqueológicos. De acordo com observações mais ou menos pontuais \\ realizadas durante as últimas três décadas sugere-se que: \\ a) A indústria lítica mais antiga parece associar-se ao nível marinho I (20-30 m a.n.m.a.m.), podendo ter sido \\ posteriormente remobilizada na sequência de processos coluvionares. A presença de bifaces e de machados de mão \\ entre os artefactos identificados remete-a para o Acheulense; \\ b) A ocorrência de bifaces muito boleados em depósitos coluvionares que recobrem o nível marinho II (10-20 m \\ a.n.m.a.m.), sugere que o seu contexto primário terá sido o referido depósito marinho; \\ c) na base do depósito do nível marinho III da Praia da Aguda ocorrem artefactos líticos enquadráveis no Acheulense \\ (presença de bifaces e de machados de mão); \\ d) nas coluviões sobre os níveis marinhos I e II existem artefactos muito eolizados - aparentemente posteriores às \\ formações marinhas e anteriores à génese das coluviões - e artefactos sem qualquer alteração física - possivelmente \\ coevos dos processos de coluvionamento. Aspetos técnicos e tipológicos observados nestes dois conjuntos artefactuais \\ permitem avançar a hipótese de se relacionarem, respetivamente, com o último período glaciar (idade mínima) e com o \\ Holocénico. \\ Palavras-chave: Indústrias líticas; Paleolítico; Geomorfologia; Vila Nova de Gaia.
}

The carved lithic artefacts from the littoral of Vila Nova de Gaia: generic characterization, geoarchaeological contextualization, problems and perspectives

The coast of Vila Nova de Gaia, south of the city of Porto, constitutes a unique geoarchaeological stretch for the study of the quaternary occupation of the western facade of Iberia. This work presents some techno-typological characteristics of the lithic industries from Vila Nova de Gaia coastline and hypotheses concerning their chronostratigraphic context are presented. According to general observations carried out during the last three decades it is suggested that:

a) The earliest lithic industry seems to be associated with marine level I (20-30 a.s.1.); however, it may have been subsequently remobilized by colluvial processes. The presence of handaxes and cleavers among the artefacts connect this assemblage with the Acheulean;

b) The presence of rolled handaxes in colluvial deposits overlying marine level II (10-20 m a.s.1.) suggests that their primary context may have been the mentioned marine level;

c) At the bottom of the marine level III deposit from Praia da Aguda $(<10 \mathrm{~m}$ a.s.l) there are lithics of Acheulean age (presence of handaxes and cleavers);

d) In the colluvial deposits overlying marine levels I and II there are lithic artefacts with a very high degree of aeolisation - apparently younger than the marine formations and older than the colluvial processes - and artefacts with no patina - possibly synchronous of the colluvia. Technical and typological features observed in these two sets suggest that the first one may date from the last glacial period (minimum age) and the second one from the Holocene.

Keywords: Lithic industries; Palaeolithic; Geomorphology; Vila Nova de Gaia.

Received: 4 July, 2016; Accepted: 25 November, 2016

\section{INTRODUÇÃO}

A existência de indústrias líticas préhistóricas no litoral a norte e a sul da foz do rio Douro foi desde há muito assinalada por diversos autores (e.g. CABRAL 1881; FONTES 1916; PINTO 1927; CORTEZ 1946; ZBYSZEWSKI 1943, 1957; BRANDÃO 1962; sobre a história das investigações no âmbito do paleolítico da região do Porto ver MONTEIRO-RODRIGUES 2000). Todavia, os artefactos que as documentavam resultavam de achados isolados e, na maior parte dos casos, sem contexto sedimentar definido.
A partir dos finais da década de 1980, um dos autores deste texto (S.M.R.) realizou prospeções arqueológicas no litoral de Vila Nova de Gaia, essencialmente em algumas áreas do setor Lavadores - Granja. Estas ações, mais do que visar a recolha exaustiva de artefactos líticos, tiveram como principal objetivo a identificação de sítios que reúnem condições geoarqueológicas susceptíveis de contextualizar os artefactos líticos em termos cronológicos e "culturais".

Foi precisamente na sequência destas prospeções que se descobriu em 1988 a estação paleolítica do Cerro (Madalena, Vila Nova de Gaia). Esca-

\footnotetext{
(1) Centro de Investigação Transdisciplinar «Cultura, Espaço e Memória» (CITCEM), sergio.fossil@gmail.com

(2) Centro de Estudos de Geografia e Ordenamento do Território (CEGOT), albgomes@gmail.com

${ }^{(3)}$ Faculdade de Letras da Universidade de Lisboa, jpcunharibeiro@letras.ulisboa.pt
} 
vada em Julho e Outubro-Novembro de 1989 (esta última, uma escavação de emergência decorrente do avanço das obras relacionadas com a construção do Parque de Campismo da Madalena) e, mais tarde, em 1992, desde logo se afigurou como um sítio de grande relevância para o estudo do Acheulense do Norte de Portugal, não só pelo número significativo de bifaces encontrados, como também pelo facto de, pela primeira vez, no âmbito regional, eles surgirem associados a um contexto estratigráfico preciso, ainda que bastante complexo (MONTEIRO-RODRIGUES \& CUNHA-RIBEIRO 1991; MONTEIRO-RODRIGUES \& SANCHES 2006; MONTEIRO-RODRIGUES 2013). Estes bifaces - mais precisamente "utensílios com configuração bifacial" em função de especificidades tecnomorfológicas - foram recentemente alvo de uma análise tecnológica preliminar que permitiu, entre outros aspectos, identificar distintas sequências de talhe subjacentes à sua produção (MONTEIRORODRIGUES \& CUNHA-RIBEIRO 2014).

Ao mesmo tempo que se realizaram os trabalhos de arqueologia, desenvolveram-se durante a mesma altura, importantes estudos no âmbito da geomorfologia, os quais suportaram a proposta de um modelo geomorfológico evolutivo da plataforma litoral da região do Porto (ARAúJo 1991). Para além da sua relevância para esse domínio científico, esses estudos foram fundamentais para a Arqueologia na medida em que deram os primeiros contributos para a compreensão dos contextos sedimentares quaternários a que se associam as indústrias líticas do litoral gaiense.

$\mathrm{O}$ conhecimento acerca das indústrias líticas presentes nesta área teve novo incremento em 2004, aquando da descoberta da estação paleolítica da Praia da Aguda. Durante o verão daquele ano foram recolhidos, em plena zona intertidal, diversos artefactos em pedra lascada, exclusivamente em quartzo. No ano seguinte verificou-se que estes artefactos provinham de um depósito de praiafóssil apenas visível durante a baixa-mar, conservado num setor deprimido da plataforma de abrasão atual, implantado a cerca de $1 \mathrm{~m}$ a.n.m.a.m. De acordo com ARAÚJO (2008) E ARAÚJO et al. (2003) trata-se de uma formação que poderá datar do Éemiano. Os materiais líticos a ela associados remetem também para o Acheulense em função da presença de bifaces e de machados de mão (MONTEIRO-RODRIGUES \& GONZÁlEZ 2010).

Não obstante o potencial arqueológico elencado, nunca foi possível aos investigadores envolvidos nestes trabalhos desenvolver programas de investigação que permitissem levar por diante as acções iniciadas nos finais da década de 1980 e assim contribuir para um melhor conhecimento das indústrias líticas do litoral de Vila Nova de Gaia.

No sentido de contrariar esta situação e de procurar num futuro próximo, dar continuidade a estas pesquisas, agora numa perspectiva interdisci- plinar, decidiu-se elaborar este texto que procura, sobretudo, fazer um balanço dos dados que se dispõe e os problemas que importará esclarecer. Neste contexto, há que sublinhar que os comentários que adiante se tecem são iminentemente preliminares uma vez que assentam em amostragens artefactuais genericamente pouco expressivas e em análises tecno-tipológicas expeditas, carecendo igualmente de mais suporte nos domínios da geoarqueologia, da geomorfologia e da sedimentologia.

Por outro lado, subjacente a este texto está também a vontade de divulgar um património geomorfológico e arqueológico que no decurso dos últimos 25 anos se tornou praticamente residual em consequência de uma política de ordenamento do território que permitiu a desmesurada urbanização da orla costeira e que não teve nunca em conta todo um conjunto de propostas para a sua salvaguarda (e.g. PDM). Por isso, não obstante a exiguidade dos dados, optou-se pela sua publicação antes que o "progresso" os faça cair num esquecimento definitivo.

\section{OS DEPÓSITOS QUATERNÁRIOS DO LITO- RAL DE VILA NOVA DE GAIA}

Os materiais líticos que servem de base ao presente estudo surgem em conexão com distintos depósitos quaternários existentes ao longo da plataforma litoral do concelho de Vila Nova de Gaia.

A plataforma litoral nos arredores da cidade do Porto suporta, frequentemente, numerosos afloramentos de depósitos genericamente classificados como "plio-plistocénicos" nas cartas geológicas de escala 1.50000 . Na figura 1 observa-se o desenvolvimento orográfico da faixa litoral situada na fachada litoral de Vila Nova de Gaia onde é possível identificar três unidades morfológicas e sedimentares principais (ARAÚJO et al. 2003):

1 - a área de colinas acima dos $130 \mathrm{~m}$ de altitude (o apelidado relevo marginal);

2 - uma rampa de fraco declive situada entre os 130 e os $50 \mathrm{~m}$ (onde ocorrem os depósitos de fácies fluvial);

3 - a área situada abaixo dos $50 \mathrm{~m}$ (onde ocorrem os depósitos de fácies marinha).

Embora o grande número de afloramentos cartografados nas cartas geológicas de Portugal (e.g., TeIXEIRA et al. 1962; OliveIRA et al. 1992) induza que se trate de uma área onde os depósitos estão bem preservados, o registo sedimentar na plataforma litoral da região do Porto está longe de ser contínuo e espesso (ARAÚJO et al. 2003). Além disso, os depósitos de fácies continental apresentam uma diversidade natural em termos sedimentológicos, a que se junta uma certa dispersão altimétrica (entre $130 \mathrm{~m}$ e $50 \mathrm{~m}$ de altitude, no sector considerado).

Assim, e numa primeira abordagem (Fig. 1), os depósitos da área em apreço podem organizar-se em dois grandes conjuntos: a) depósitos de fácies 

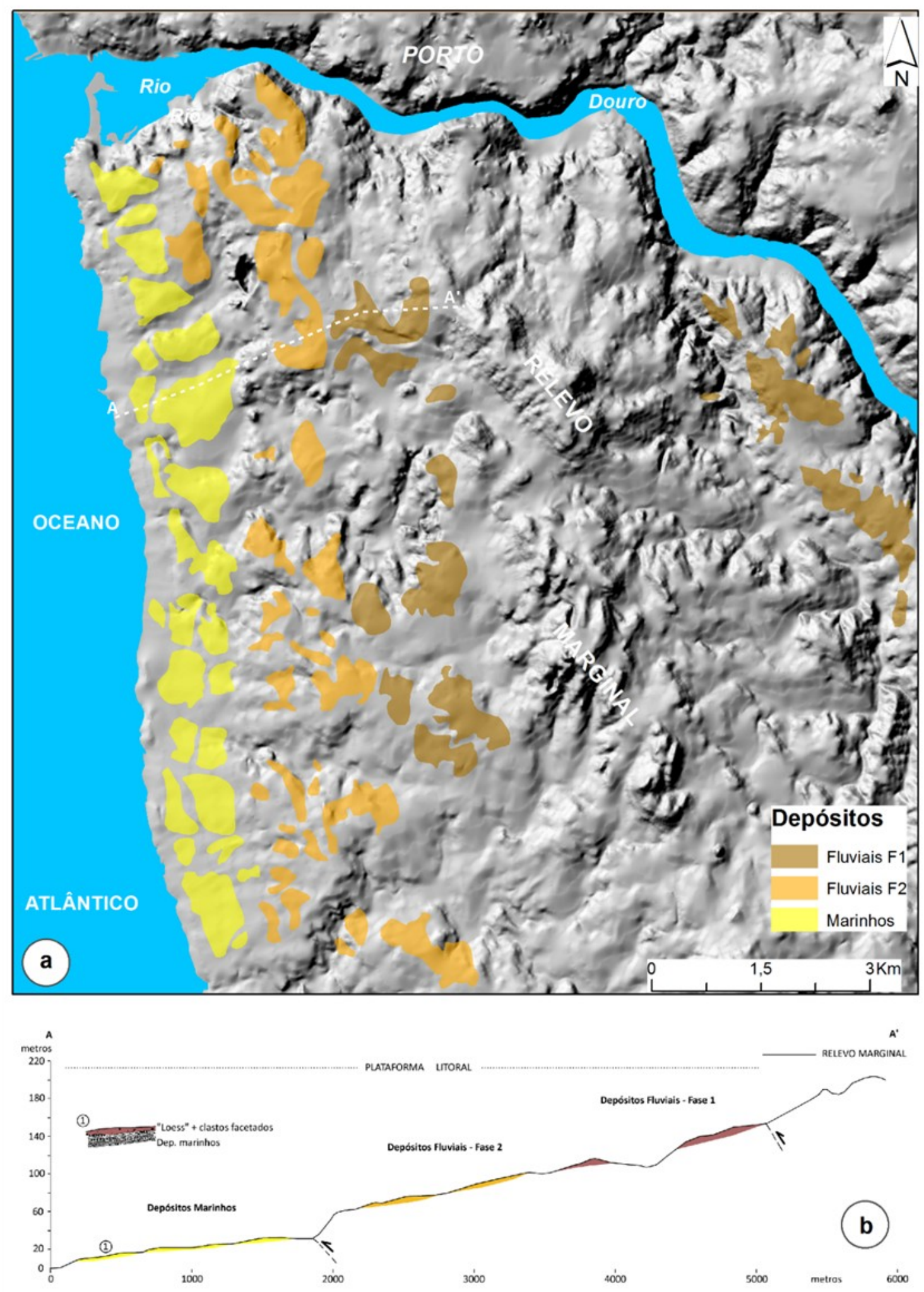

Fig. 1. Os depósitos sedimentares na faixa litoral de Vila Nova de Gaia: a) Localização dos depósitos sedimentares segundo a Carta Geológica de Portugal na escala 1/50000, folhas 9-C (Porto) e 13-A (Espinho); b) Perfil topográfico representativo da disposição dos terraços sedimentares na faixa litoral de Vila Nova de Gaia.

Fig. 1. The sedimentary deposits along the coastal strip of Vila Nova de Gaia: a) Location of the sedimentary deposits according to the Geological Map of Portugal in the scale 1/50000, sheets 9-C (Porto) and 13-A (Espinho); b) Topographic profile representative of the sedimentary terraces arrangement in the coastal strip of Vila Nova de Gaia. 
continental, que ocorrem acima dos 50m; b) depósitos marinhos, que se encontram abaixo dos $40 \mathrm{~m}$.

No conjunto dos depósitos fluviais (Fig. 1) é possível fazer uma distinção entre depósitos superiores (FASE I) e inferiores (FASE II). Os primeiros estão relacionados com ambientes de baixa energia, e provavelmente depositaram-se ao longo de uma planície litoral; os depósitos mais baixos e mais recentes são mais grosseiros e apresentam forma e fácies típicas de leque aluvial (GOMES \& ARAÚJO 2005). Há uma clara evidência da existência de duas fases de desenvolvimento geomorfológico: os depósitos aluviais mais recentes, avermelhados, contém, em vários lugares, blocos esbranquiçados que são restos dos depósitos mais antigos. A destruição de uma antiga cobertura sedimentar sugere a mudança de um ambiente sedimentar de baixa inclinação para uma paisagem onde o soerguimento das encostas forneceu alguns blocos (mais de $50 \mathrm{~cm}$ de largura).

Os depósitos fluviais revelam outra diferença: as fortes couraças de ferro desaparecem dos antigos para os mais recentes, o que pode representar a mudança das condições climáticas tropicais que prevaleceram em regiões mais temperadas durante o Mioceno e Plioceno inferior e que se modificam no final do Plioceno e durante o Quaternário (GOMES \& ARAÚJO 2005).

Entre depósitos fluviais e marinhos existe um degrau topográfico bastante retilíneo que pode chegar a 30m de desnível (Fig. 1). Este elemento sugere que, durante o Quaternário, a parte ocidental da plataforma litoral deve ter cedido ao longo de uma falha submeridiana (ARAÚJO et al. 2003), o que permitiu a erosão e sedimentação marinha sobre o compartimento tectónico subsidente. Esta escarpa de falha foi retrabalhada pela ondulação costeira durante o nível mais alto do mar e pode ser considerada uma arriba fóssil.

Os depósitos marinhos pleistocénicos ocupam apenas a franja ocidental da plataforma litoral, 1-2 km de largura e sempre abaixo dos $40 \mathrm{~m}$ de altitude (Fig. 1a e b).

Estes depósitos podem ser divididos, pelo menos, em três níveis. A distinção entre eles está na sua natureza sedimentológica, principalmente na cor, na erosão da rocha onde assentam, na análise de minerais de argila e no grau de consolidação (ARAÚJO et al. 2003). Como estamos numa área em soerguimento, os terraços mais elevados são também os mais antigos. Esses três níveis não aparecem juntos ao longo do litoral, faltando por vezes, um ou dois níveis na sequência da escadaria. O único lugar onde todos eles são visíveis é Lavadores, um local imediatamente ao sul da Foz do Douro, pelo que se apresenta a escadaria com as altitudes referidas aos afloramentos de Lavadores: Nível I - o mais alto e mais antigo (entre 40 e $30 \mathrm{~m}$ de altura), com depósitos bastante grossei- ros, sobre rocha muito alterada e avermelhada; Nível II - em posição intermédia (de 20 a $10 \mathrm{~m}$ ), com intenso desgaste da rocha, mas de cor esbranquiçada; Nível III - (de $10 \mathrm{~m}$ até ao n.m.a.m.), os mais baixos e considerados como eemianos, constituem normalmente depósitos cimentados por ferro em que a base não está alterada, apresentando apenas uma "pâtine" de ferro (ARAÚJO 2008).

A cobrir, quer o bed-rock, quer os diversos depósitos plio-pleistocénicos encontram-se depósitos solifluxivos contemporâneos da última glaciação (ARAÚJO et al. 2003). Durante esse período e no Holocénico há, ainda, testemunhos de depósitos eólicos e lagunares com grande interesse para a identificação de variações climáticas e do nível do mar ocorridas nos últimos 125.000 anos.

\section{AS INDÚSTRIAS LÍTICAS DO LITORAL DE VILA NOVA DE GAIA}

Os artefactos líticos do litoral de Vila Nova de Gaia - num total de 1129 exemplares - foram recolhidos em diversos pontos do setor prospetado, em locais onde ocorrem diferentes tipos de formações sedimentares com as quais eles estarão relacionados (Fig. 2).

\subsection{Depósito marinho do nível I e respeti- vas coberturas coluvionares}

A maior parte dos artefactos líticos recolhidos nos locais implantados sobre a formação marinha do nível I (Quadro 1) provém de depósitos coluvionares que normalmente a recobrem e/ou ravinam. Não obstante, não há actualmente qualquer dúvida quando à existência de materiais talhados no depósito marinho, anteriores, portanto, à génese das referidas coluviões. Na área do Cerro (CMcE) (MonTEIRORODRIGUES \& CUNHA-Ribeiro 2014) e na RJMCP, em cortes resultantes de trabalhos de construção civil, identificaram-se artefactos com ligeiro boleamento no nível de praia fóssil (nomeadamente um biface na RJMCP) (Fig. 3).

Relativamente à estação paleolítica do Cerro aceita-se a hipótese dos materiais identificados na denominada unidade estratigráfica $\mathrm{C} 4$ ("coluvião antiga") e na base da sequência sedimentar de certas áreas intervencionadas, nomeadamente nos interstícios do bedrock (Fig. 4) - contextos em que abundam os utensílios com configuração bifacial conectados com o Acheulense - serem também correlativos do depósito marinho, tendo sido, posteriormente, capturados pela referida coluvião (MONTEIRO-RoDRIGUES \& CUNHA-RIBEIRO 1991 2014). A ausência de vestígios de rolamento neste conjunto artefactual explicar-se-ia pelo seu rápido soterramento no decurso de um "evento" transgressivo, possivelmente semelhante ao que poderá ter ocorrido na Praia da Aguda numa época significativamente mais tardia (vide infra). 
Os artefactos líticos talhados do litoral de Vila Nova de Gaia: caracterização genérica, contextualização geoarqueológica, problemas e perspectivas

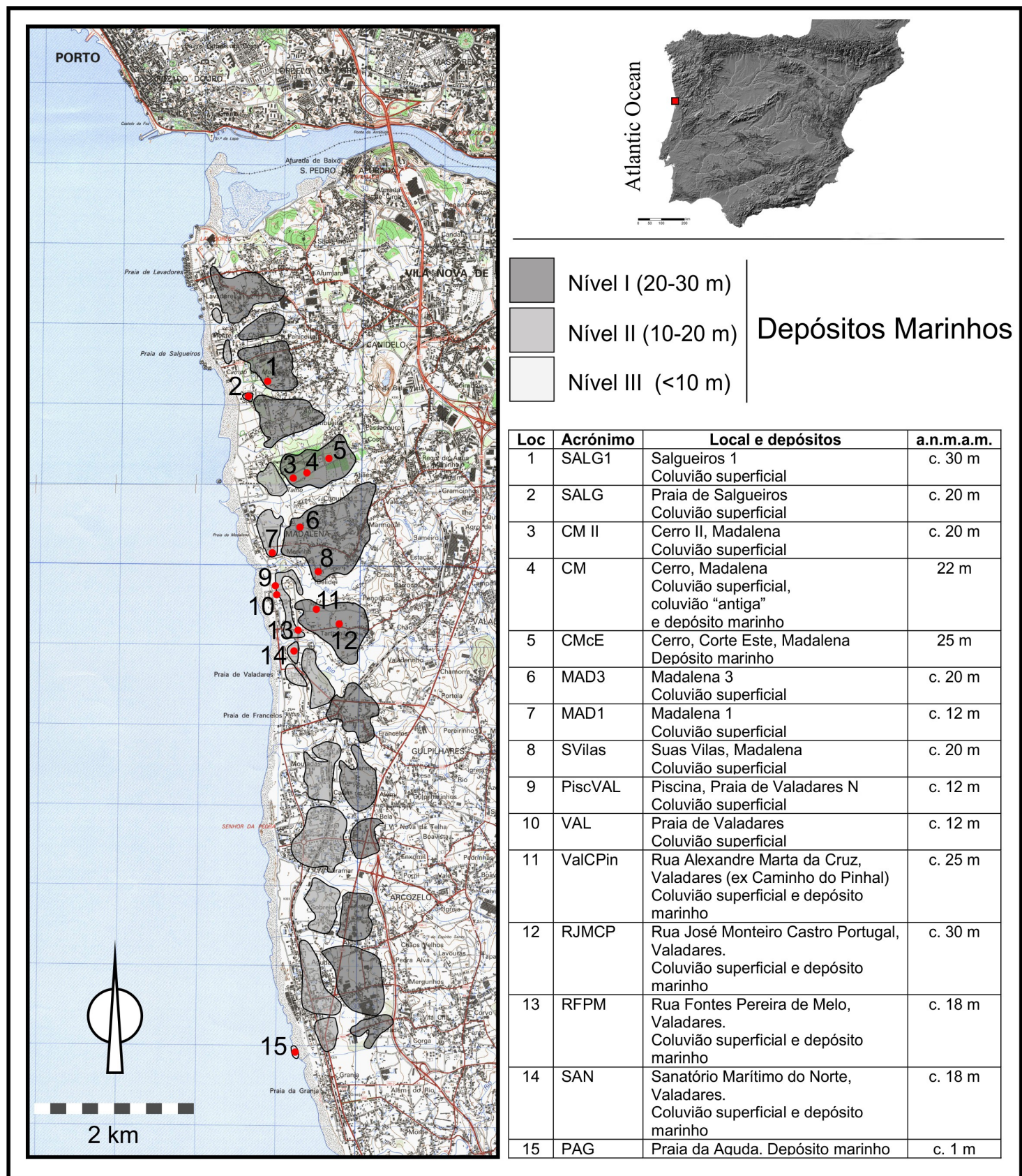

Fig. 2. Localização dos sítios onde foram identificados artefactos líticos talhados em extratos da Carta Militar de Portugal na escala 1/25000, folhas 122 (Porto) e 133 (Valadares). A representação dos vários níveis marinhos teve como base a Carta Geológica de Portugal na escala 1/50000, folhas 9-C (Porto) e 13-A (Espinho).

Fig. 2. Location of the sites where lithics were found in extracts of the Carta Militar de Portugal na escala 1/25000, sheets 122 (Porto) and 133 (Valadares). The representation of the different marine levels is based on Carta Geológica de Portugal na escala 1/50000, folhas 9-C (Porto) e 13-A (Espinho). 
Quadro 1 - Quantificação dos artefactos líticos por sítio arqueológico do nível I Table 1 - Quantification of lithics by archaeological site from level I.

\begin{tabular}{|c|c|c|c|c|c|c|}
\hline CM & RJMCP & SALG 1 & SVilas & Mad 3 & ValCPin & Total \\
\hline $\begin{array}{c}616 \\
\text { Escavação-339 }\end{array}$ & 13 & 23 & 7 & 8 & 15 & 682 \\
$\begin{array}{c}\text { Superficie - 78 } \\
\text { CM II - 198 } \\
\text { CMcE - 1 }\end{array}$ & & & & & & \\
\hline
\end{tabular}

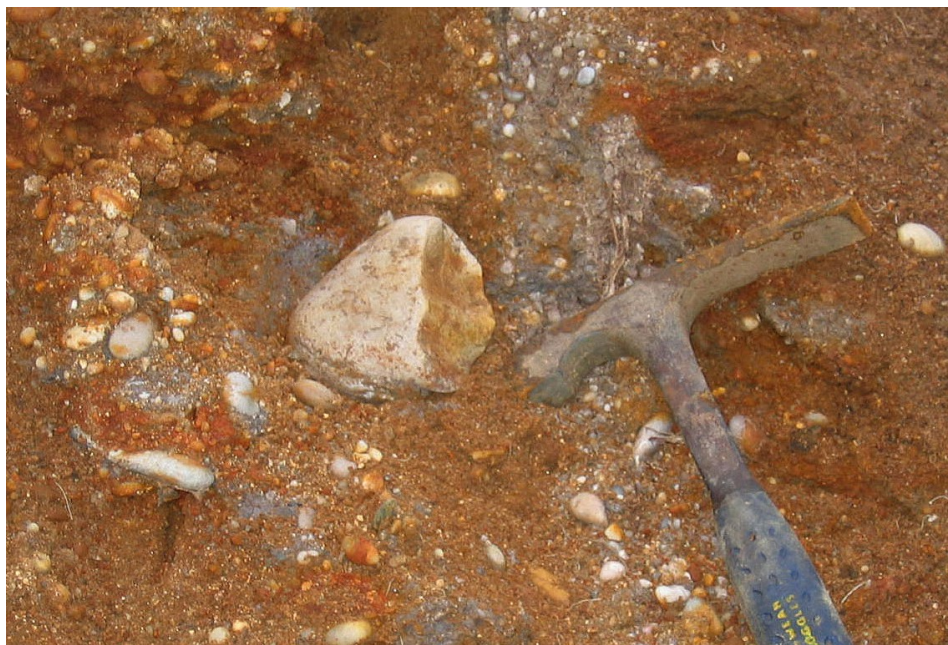

Fig. 3. Núcleo in situ no depósito marinho visível no corte CMcE (nível I).

Fig. 3. Core in situ in the marine deposit, found in the cross-section of CMcE (level I).

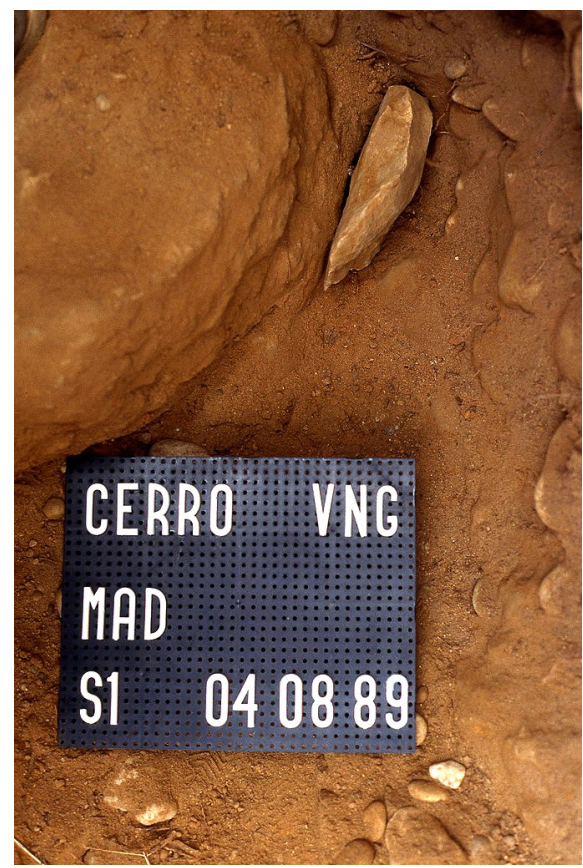

Fig. 4. Estação paleolítica do Cerro: machado de mão (sem rolamento) localizado num interstício do bedrock granítico.

Fig. 4. The Palaeolithic site of Cerro: cleaver (with no patina) found in an interstice of the granite bedrock. 
É de salientar, porém, que a morfologia e as dimensões dos seixos rolados que servem de suporte a estes materiais líticos paleolíticos não condizem com as observadas nos clastos do nível conservado da praia fóssil, os quais são normalmente muito pequenos; condizem sim com as dos seixos associados a depósitos fluviais, implantados a cotas mais elevadas (ARAÚJO 1991). Tal facto sugere a existência de uma estratégia de selecção dos suportes utilizados, eventualmente favorecida pela ocorrência de processos geomorfológicos (inclusive tectónicos, seg. ARAÚJO 1991) que promoveriam o desmantelamento das formações fluviais mais antigas, tornando os respetivos seixos acessíveis.

Igualmente no Cerro, mas na unidade estratigrafica $\mathrm{C} 2$ - um depósito superficial aparentemente do tipo debris flow (MONTEIRO-RODRIGUES \& CUNHA-RIBEIRO 1991, 2014) - recolheram-se inúmeros artefactos muito boleados, incluindo bifaces, seguramente retomados das formações subjacentes, nomeadamente da já referida coluvião $\mathrm{C} 4 \mathrm{e}$, possivelmente, do nível marinho I. Uma vez que a maior parte dos materiais líticos destes depósitos mais anti- gos não evidenciam rolamento (se existe é ténue) terse-á de aceitar que esta característica física terá sido adquirida na sequência da sua remobilização. A ser assim, os processos que deram origem à formação $\mathrm{C} 2$ terão implicado uma energia considerável e de longa duração não compatível com um fluxo de detritos.

A par dos artefactos relacionáveis directa ou indirectamente com o nível marinho I ocorrem também, nas coluviões superficiais, objectos líticos claramente posteriores à praia fóssil, podendo mesmo alguns deles datar já do Holocénico. A título de exemplo refira-se uma lasca e um flanco de núcleo prismático, ambos em sílex com tratamento térmico, um núcleo sobre cristal de quartzo fumado, um "peso de rede" sobre seixo de quartzito e diversos seixos talhados (núcleos?) de pequenas dimensões, em quartzito e quartzo, com um número elevado de extracções, por vezes remontantes, escalariformes e com muitos ressaltos (MEIRELES 1992, 2009) (Fig. 5). De um modo geral, estes materiais apresentam-se "frescos" ou com ténue eolização, havendo um ou outro caso de peças com dupla pátina (eolizado + "fresco" e boleado + "fresco").
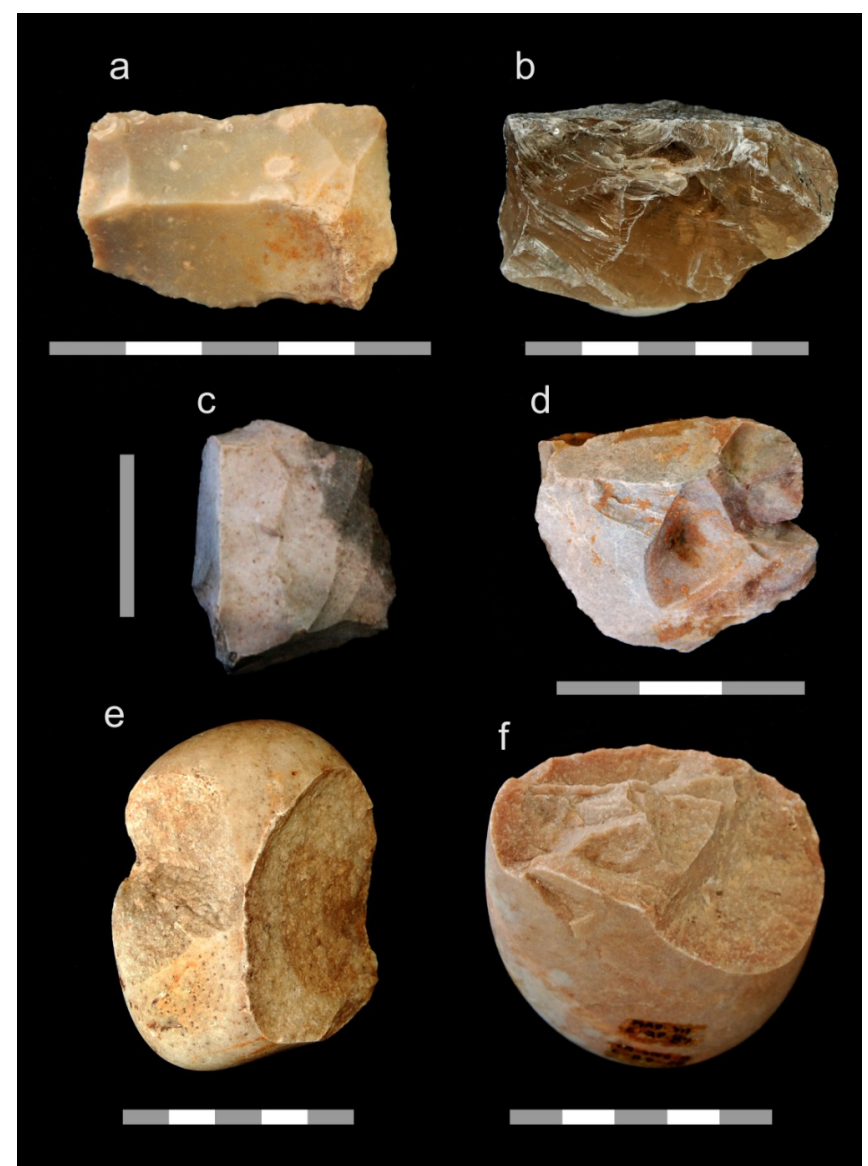

Fig. 5. Artefactos líticos de provável cronologia holocénica. A: Lasca em sílex. B: Núcleo sobre cristal de quartzo fumado. C: Flanco de pequeno núcleo prismático em sílex com tratamento térmico. D: Lasca em sílex com tratamento térmico. E: "Peso de rede" em quartzito. F: Seixo talhado unifacial (núcleo?) com um elevado número de pequenas extrações. Fig. 5. Lithics probably of Holocene age. A: Flint flake. B: Core on smoky quartz crystal. C: Small prismatic core flank on flint with heat treatment. D: Flint flake with heat treatment. E: "Net sinker" on quartzite. F: Chopper (core?) with a high number of small flake scars. 
Evidenciando estados físicos semelhantes, surgem ainda alguns núcleos com extracções centrípetas e pequenas lascas Levallois atípicas, pelo que não é de descurar a possibilidade da existência, neste contexto sedimentar, de uma indústria lítica conectável com fases mais avançadas do Paleolítico (Paleolítico médio?) ou mesmo posterior a este período (MEIRELES 1991, 2009) (Figs. 6 e 7).

No seu conjunto, os materiais líticos recolhidos nos depósitos implantados sobre o nível I foram produzidos maioritariamente a partir de seixos rolados de quartzito (575), havendo $90 \mathrm{em}$ quartzo, 13 em corneana, 3 em sílex e 1 em cristal de quartzo fumado. Tais artefactos distribuem-se pelas categorias elencadas no quadro 2 .

Em relação aos núcleos observa-se um claro predomínio dos grupos técnicos que refletem estratégias expeditas de produção de lascas, bem adequadas à exploração de seixos rolados de quartzito e quartzo, ou seja, o grupo II (79), o grupo III (22) e o grupo V (28) (SANTONJA 1984-1985). Por seu turno, os métodos de debitagem centrípeta, uni e bifacial, com e sem preparação do plano de percussão, revelam-se bem menos expressivos (VIb-2, VIc-8, VII-7) (idem). Os núcleos "diversos”, com sequências de extracção algo aleatórias, são igualmente relevantes (21), traduzindo também eles acções que visam a exploração oportunista de blocos normalmente irregulares. O grupo I está documentado por apenas 12 núcleos, o grupo IV por $3 \mathrm{e}$ o método Kombewa por 1 (ainda que no Cerro ocorram várias lascas com uma ou duas extracções avulsas na face plana)

As lascas, por sua vez, possuem maioritariamente talões corticais (149), seguindo-se as com talão liso (74), as com talão indeterminável devido a fratura ou supressão intencional (26) e as com talão diedro (2, uma das quais correspondendo a uma lasca Levallois atípica). A importância dos talões corticais poderá indiciar a preponderância do talhe unifacial em detrimento do bifacial, aspecto que aliás tem sido referido em relação às indústrias líticas do litoral norte do País (MeIRELEs 1992, 2009).

Quanto aos bifaces, procedeu-se recentemente ao estudo tecnológico dos exemplares do Cerro, o qual permitiu identificar sete sequências de talhe subjacentes à sua produção (MONTEIRORODRIGUES \& CUNHA-RIBEIRO 2014). Tais sequências, de carácter expedito e aparentemente estruturadas em função das características dos suportes utilizados, visaram "a obtenção de (...) artefacto[s] de morfologia apontada, cuja extremidade distal se destaca da volumetria geral da peça, através de uma maior ou menor extensão e amplitude do talhe dos bordos adjacentes, conservandose ao mesmo tempo, em posição proximal, uma expressiva zona espessa, frequentemente sem qualquer alteração do suporte original" (MONTEIRORODRIGUES \& CUNHA-RIBEIRO 2014: 16), correspondendo à denominada "unidade tecno-funcional de preensão" (idem).

Dois exemplares não incluídos no referido estudo - um da RJMCP e outro de ValCPin -, produzidos a partir de seixos rolados de quartzito, correspondem, respectivamente, a um biface parcial com extremidade distal arredondada, obtido por talhe sequencial (sequência operatória 5), e a um uniface (sequência operatória 3) com extremidade distal apontada (idem) (Fig. 8).

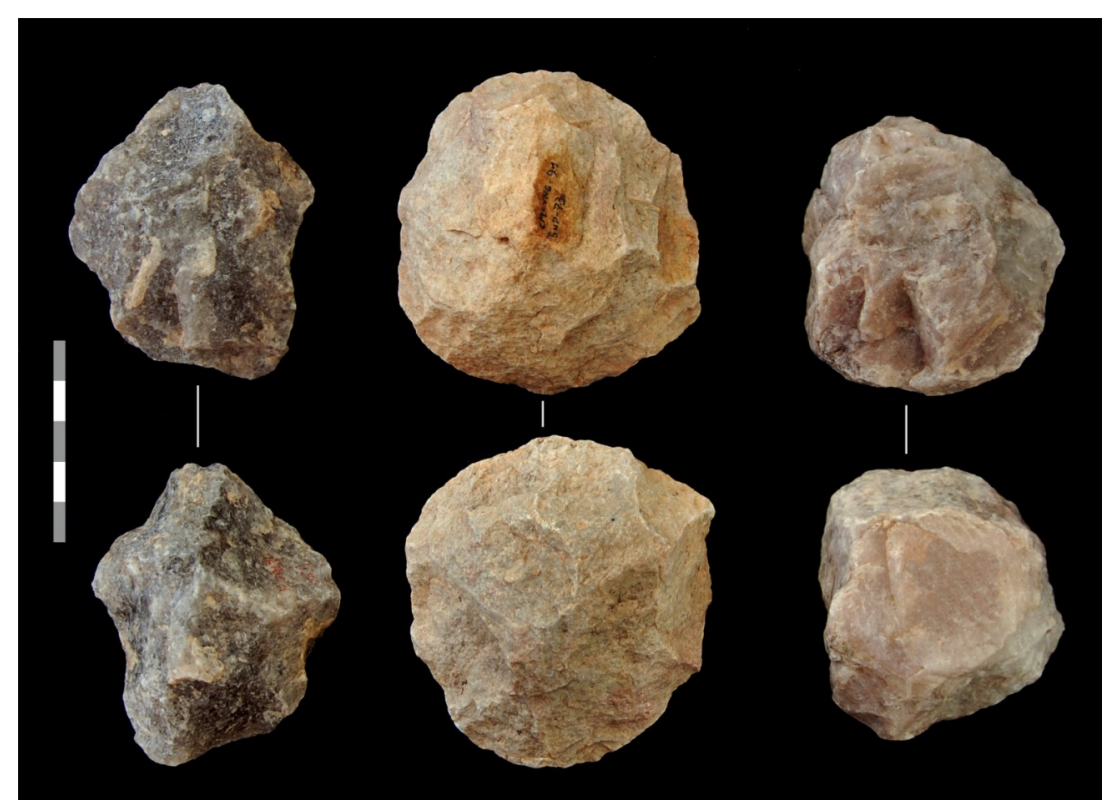

Fig. 6. Núcleos com debitagem centrípeta bifacial.

Fig. 6. Cores with centripetal bifacial debitage. 
Os artefactos líticos talhados do litoral de Vila Nova de Gaia: caracterização genérica, contextualização geoarqueológica, problemas e perspectivas

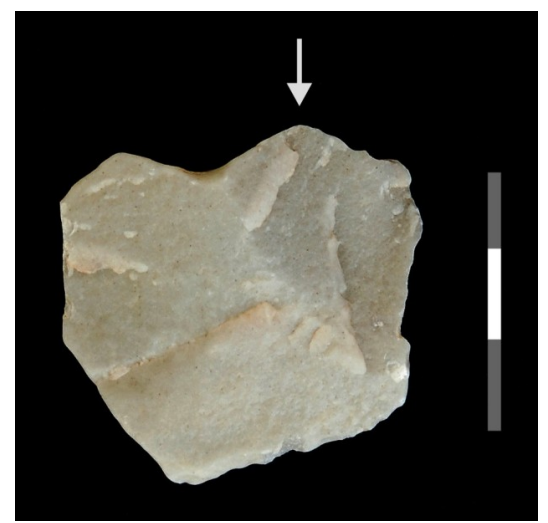

Fig. 7. Lasca Levallois atípica.

Fig. 7. Atypical Levallois flake.

Quadro 2. Distribuição quantitativa das diversas categorias de artefactos líticos recolhidos nos depósitos associados ao nível marinho I.

Table 2 . Quantitative distribution of the different categories of lithics found in the deposits associated with marine level I.

\begin{tabular}{|c|c|c|c|c|c|c|c|}
\hline & $\mathrm{CM}$ & RJMCP & SALG 1 & SVilas & Mad 3 & ValCPin & Total \\
\hline Núcleos & $160 *$ & 2 & 7 & 5 & 2 & 7 & 183 \\
\hline Lascas & 226 & 3 & 11 & 2 & 4 & 5 & 251 \\
\hline Bifaces/Unifaces & $\begin{array}{c}120 \\
\text { Unif--15 } \\
\text { Bif.-105 }\end{array}$ & 1 & -- & -- & -- & $\begin{array}{c}1 \\
\text { Unif.-1 }\end{array}$ & 122 \\
\hline Machados de mão & 4 & -- & -- & -- & -- & -- & 4 \\
\hline Triedros & 2 & -- & -- & -- & -- & -- & 2 \\
\hline Seixos talhados & $\begin{array}{c}42 \\
\text { Unif.-35 } \\
\text { Bif.-7 }\end{array}$ & $\begin{array}{c}6 \\
\text { Unif.-5 } \\
\text { Bif.-1 }\end{array}$ & $\begin{array}{c}4 \\
\text { Unif.-4 }\end{array}$ & -- & $\begin{array}{c}2 \\
\text { Unif.-2 }\end{array}$ & -- & 54 \\
\hline $\begin{array}{l}\text { Utensílios } \\
\text { lasca }\end{array}$ & 9 & 1 & 1 & -- & -- & -- & 11 \\
\hline Peso de rede & 1 & -- & -- & -- & -- & -- & 1 \\
\hline Utensílios diversos & 50 & -- & -- & -- & -- & 1 & 51 \\
\hline Inclassificáveis & 2 & -- & -- & -- & -- & 1 & 3 \\
\hline Total & 616 & 13 & 23 & 7 & 8 & 15 & 682 \\
\hline
\end{tabular}

*Inclui o núcleo recolhido em CMcE

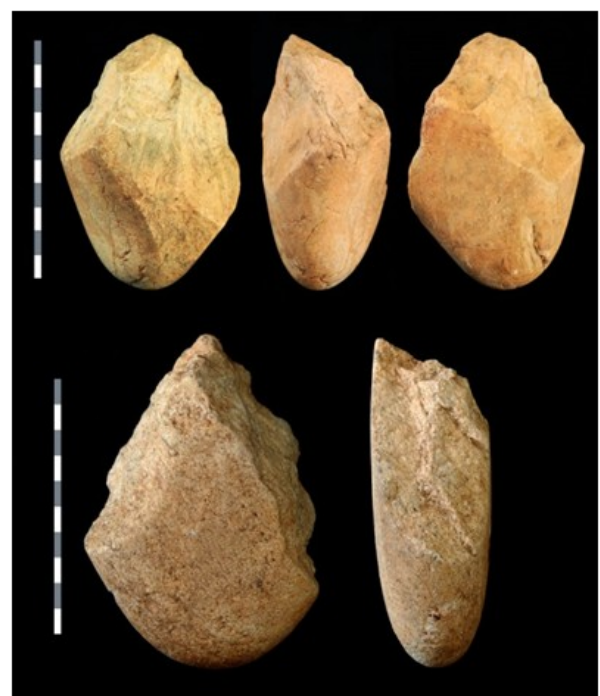

Fig. 8. Em cima: biface recolhido na RJMCP, no depósito marinho do nível I. Em baixo: uniface proveniente de coluvião sobre o depósito marinho do nível I (ValCPin).

Fig. 8. Top: Handaxe found in RJMCP, in the marine deposit of level I. Bottom: Uniface found in the colluvial deposit overlying the marine deposit of level I. 
Os machados de mão e os triedros, identificados até ao momento apenas no Cerro, podem considerar-se utensílios excepcionais. Em relação aos primeiros, tal facto decorre muito provavelmente da quase inexistência, nos diversos tipos de depósito, de clastos susceptíveis de fornecer lascas adequadas à sua produção (CUNHA-RIBEIRO et al. 1990). Dois dos quatro exemplares recolhidos - um do tipo $0 \mathrm{e}$ um do tipo I (TIXIER 1956; CUNHA-RIBEIRO 1999) foram talhados sobre calote de seixo, pelo que se consideram peças atípicas; os restantes dois - dos tipos I e V (idem) - utilizaram lascas como suporte (Fig. 9). Os triedros, documentados por duas peças produzidas a partir de seixos rolados de quartzito, exibem pontas bem destacas e bases corticais espessas. Trata-se de peças bastante interessantes do ponto de vista técnico e morfológico, carecendo ainda de análise mais detalhada.

No que respeita aos seixos talhados - num total de 54 - verifica-se um claro predomínio dos unifaciais (46), ocorrendo apenas 8 bifaciais. Tal facto poderá corroborar a hipótese avançada acerca da relevância do talhe unifacial no quadro das indústrias líticas do noroeste português (MEIRELES 1992, 2009). Os respectivos gumes são maioritariamente simples (45), sendo os apontados residuais (9). Ao contrário do que sucede no litoral minhoto (idem), os seixos talhados do sector costeiro de Vila Nova de Gaia parecem constituir uma categoria artefactual pouco expressiva.

Os utensílios sobre lasca estão representados por apenas 11 exemplares, incluindo-se nesta categoria essencialmente raspadores, entalhes e um furador (Fig. 10). Os denominados "utensílios diversos" (51) foram produzidos a partir de diferentes tipos de suporte e englobam artefactos com alguma variedade tipológica (furadores, raspadores sobre calote de seixo, raspadores sobre seixo, utensílio apontado, entre outros).

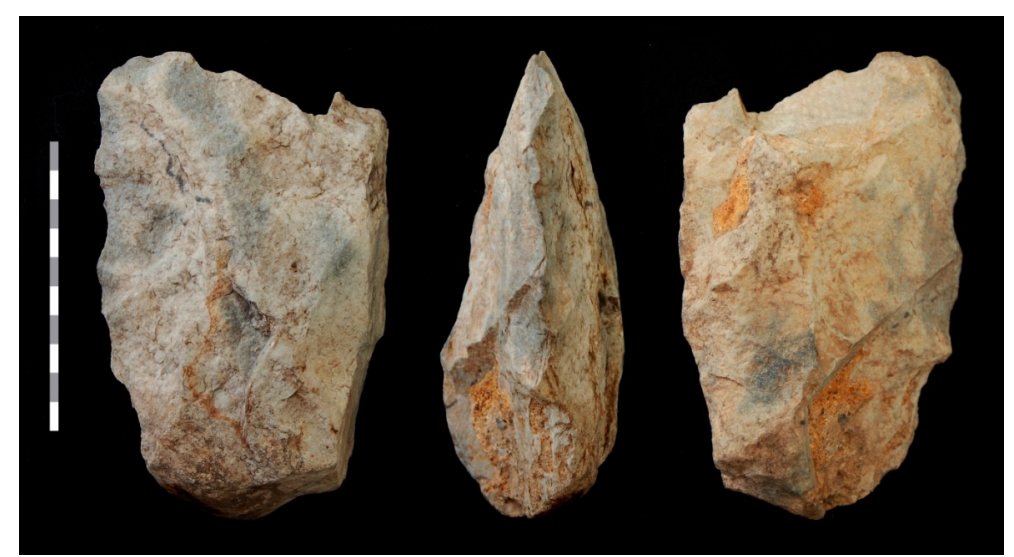

Fig. 9. Machado de mão do tipo V proveniente da estação paleolítica do Cerro (gume ligeiramente fracturado).

Fig. 9. Cleaver of type V from the Palaeolithic site of Cerro (with broken edge).

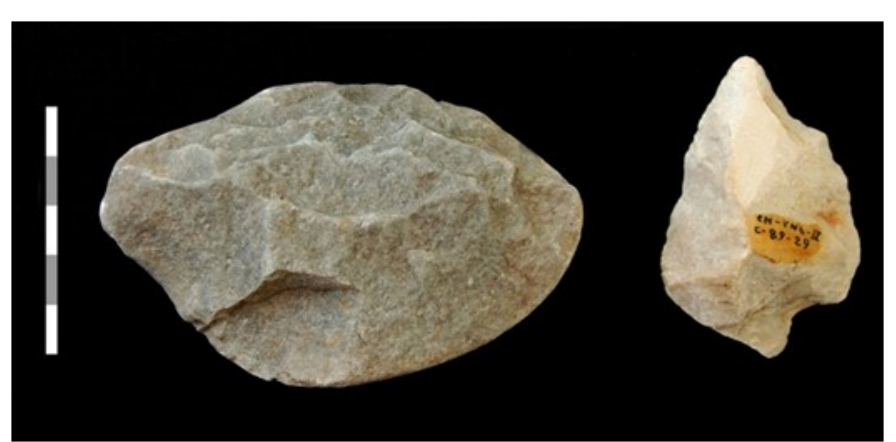

Fig. 10. Utensílios sobre lasca da estação paleolítica do Cerro: raspador convexo (à esquerda) e furador atípico.

Fig. 10. Flake tools from the Palaeolithic site of Cerro: scraper (left) and atypical awl. 


\subsection{Depósito marinho do nível II e respecti- vas coberturas coluvionares}

Os materiais líticos recolhidos nos sítios implantados sobre o nível marinho II provêm unicamente de coluviões (Quadro 3). No entanto, tendo em conta o nítido boleamento e, nalguns casos, a alteração físico-química evidenciada por algumas peças, pode aceitar-se a existência de uma indústria relacionável com o depósito marinho. Uma vez que esta indústria engloba bifaces (2) é possível enquadrá-la no âmbito do tecno-complexo Acheulense (Fig. 11).

Outros artefactos, eolizados a intensamente eolizados, deverão ser mais recentes que os anteriores dado que entre eles ocorrem objectos com negativos com dupla pátina: uns boleados e outros (posteriores) apenas eolizados (boleamento + eolização) (Fig. 12). Esta eolização terá afectado igualmente a superfíce de artefactos rolados, aparentemente relacionados, como se referiu, com o nível marinho.

Um terceiro conjunto de objetos líticos, também detetado nos depósitos coluvionares, engloba peças sem boleamento e sem deflação. A igual presença de materiais com negativos com dupla pátina - uns rolados e/ou eolizados, outros sem qualquer alteração física - permite colocar a hipótese deste conjunto ser, eventualmente, o mais recente. A recolha na superfície de diversas coluviões de pesos de rede (p.e. em SALG), de pequenos núcleos do grupo II com extrações abruptas, remontantes e escalariformes (MEIRELES 1992, 2009), e de uma lasca em sílex, todos com negativos "frescos", indicia a existência, neste conjunto, de artefactos que poderão ter sido produzidos já durante o Pós-glaciar (Fig. 12).

Quadro 3. Quantificação dos artefactos líticos por sítio arqueológico do nível II Table 3. Quantification of lithics by archaeological site from level II.

\begin{tabular}{|l|l|l|l|l|l|l|}
\hline SAN & RFPM & VAL & PiscVAL & MAD 1 & SALG & Total \\
\hline 110 & 43 & 26 & 24 & 55 & 33 & 291 \\
\hline
\end{tabular}

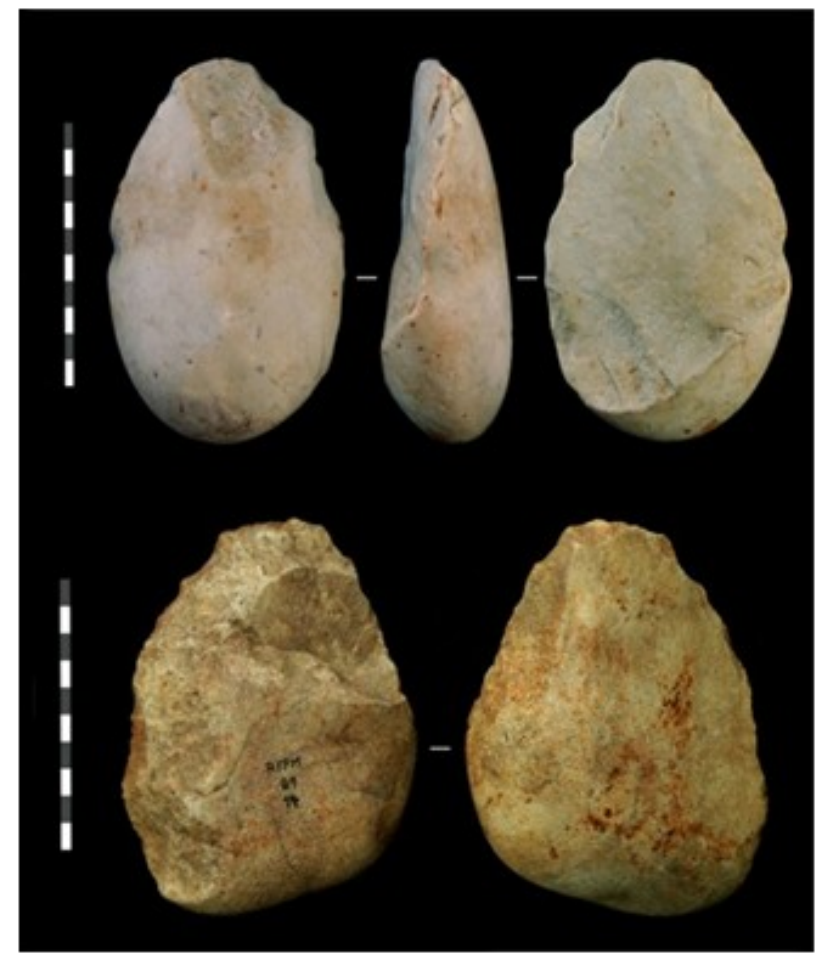

Fig. 11. Em cima: biface parcial sobre lasca de quartzito muito rolado. Em baixo: biface parcial sobre seixo de quatzito parcialmente rolado e com alteração físico-química.

Fig. 11. Top: Partial handaxe on quartzite flake, with high degree of roundness. Bottom: Partial handaxe on quartzite pebble partially rolled and with physicochemical alteration. 


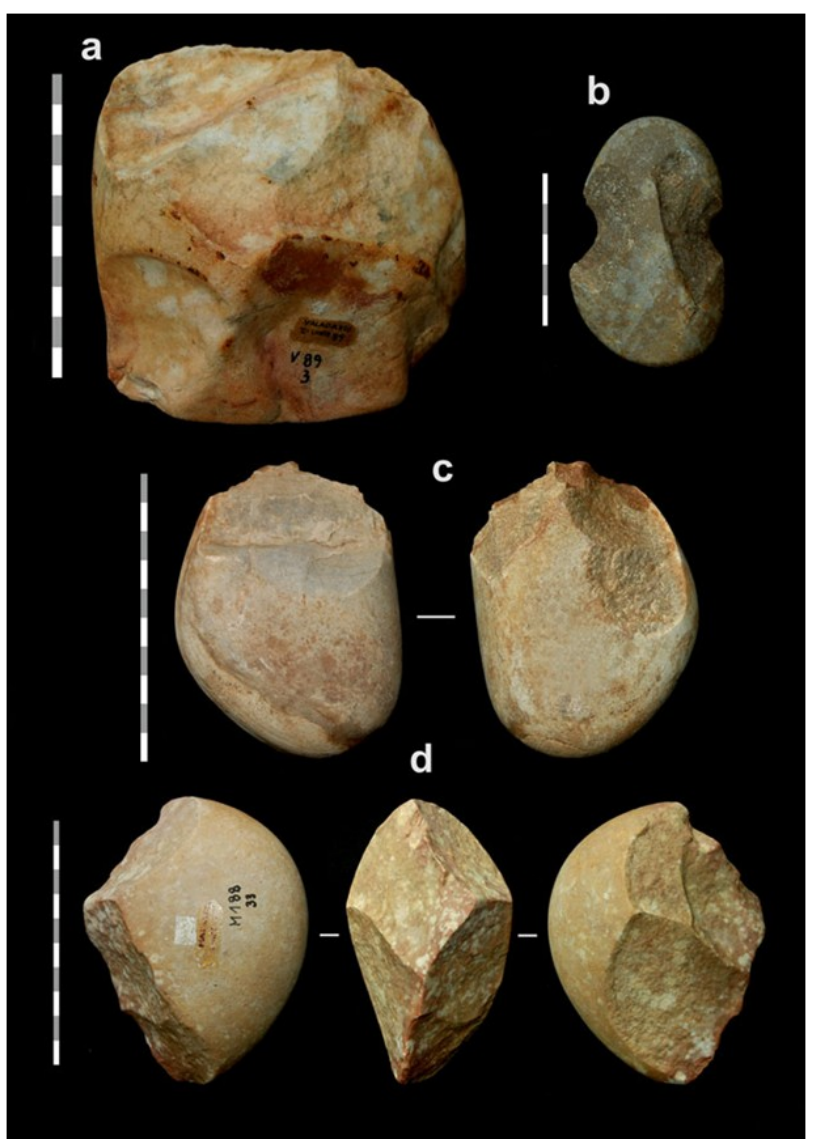

Fig. 12. A: Núcleo do grupo II com dupla pátina (muito boleado + eolizado e sem rolamento). B: "Peso de rede" sem qualquer alteração física. C: Núcleo do grupo II com dupla pátina (muito eolizado + "fresco"). D: Núcleo do grupo V fortemente eolizado.

Fig. 12. A: Core of the group II with double patina (rolled + aeolised and not rolled). B: "Net sinker" with no patina. C: Core of the group II with double patina (high degree of aeolisation + no patina). D: Core of the group V with high degree of aeolisation.

Observando a totalidade dos materiais líticos identificados nos depósitos associados ao nível II (Quadro 4) constata-se que a sua grande maioria foi produzida a partir de seixos rolados de quartzito (256), seguindo-se os de quartzo (31) e os de corneana (3). O sílex é residual (1).

No que concerne aos núcleos, predominam os do grupo técnico II (53), seguindo-se os explorados segundo estratégias de debitagem centrípeta, uni e bifacial, perfazendo um total de 19 peças (VIb-4, VIc-8, VII-7), e os do grupo V (Fig. 13), num total de 9 exemplares. Os restantes grupos identificados, inserindo-se, tal como o grupo II, em categorias consideradas simples e expeditas, podem considerar -se residuais (I-1, III-3 e IV-3). Assinala-se também a presença de 3 núcleos Kombewa ("esboços") e de outros 10 explorados através de sequências de debitagem diversificas, também elas expeditas.

Ainda em relação aos núcleos com debitagem centrípeta é de referir que à exceção de dois do grupo VIc claramente boleados, todos os restantes se ligam ao conjunto eolizado/muito eolizado e ao conjunto "fresco", o que permite colocar a hipótese de um certo incremento deste método em etapas cronológicas já posteriores à génese do depósito marinho do nível II (Fig. 13).

Entre as lascas destacam-se as com talão cortical (98), ocorrendo em menor número as com talão liso (34). Tal facto poderá indicar a preponderância do talhe unifacial face ao bifacial, tal como aliás parece suceder no nível I. Os talões diedros são praticamente inexistentes (1) e o único facetado associa-se a uma pequena lasca com negativos centrípetos na superfície dorsal que pode considerar-se Levallois. Um outro exemplar deste tipo, eventualmente uma lasca Levallois preferencial atípica, possui talão cortical e, igualmente, levantamentos dorsais centrípetos (Fig. 14). Em 18 exemplares não foi possível proceder à caracterização dos talões devido à sua supressão intencional e/ou a fracturas ${ }^{1}$. 


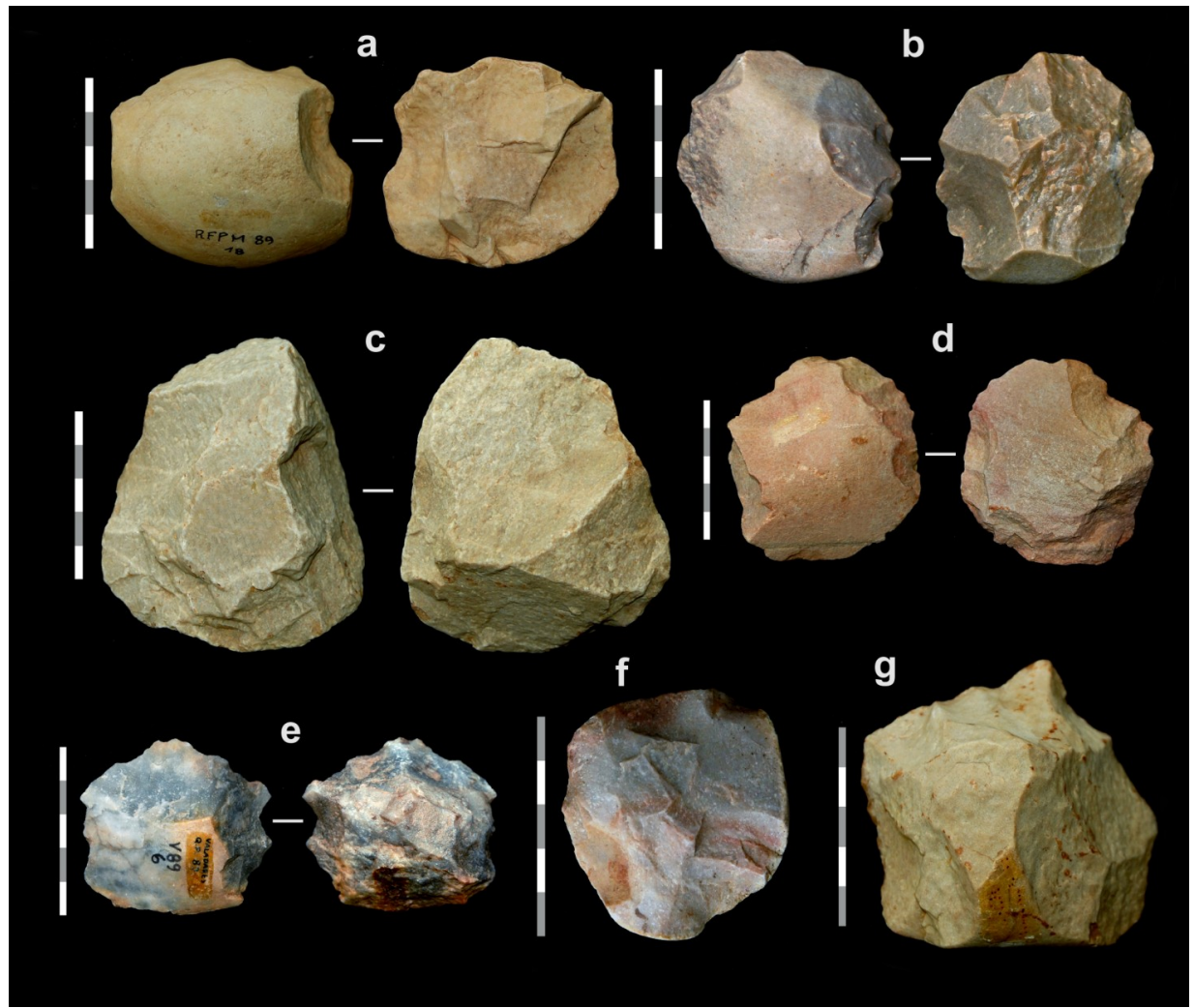

Fig. 13. Núcleos de debitagem centrípeta muito eolizados (a, b, c, g) e sem alteração física (d, e, f), supostamente posteriores à génese do nível marinho II.

Fig. 13. Centripetal cores with high degree of aeolisation (a, b, c, g) and without aeolisation (d, e, f), allegedly subsequent to the formation of the marine level II.

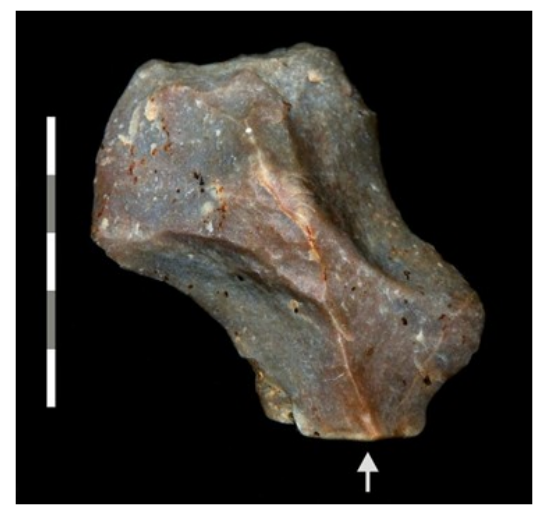

Fig. 14. Lasca Levallois preferencial atípica com talão cortical, intensamente eolizada.

Fig. 14. Atypical preferential Levallois flake with cortical butt and high degree of aeolisation.

Os dois bifaces recolhidos neste contexto apresentam talhe bifacial parcial e resultam da operacionalização da sequência operatória 4 (MONTEIRO-RODRIGUES \& CUNHA-RIBEIRO 2014). Um deles, com simetria bilateral e extremidade distal arredondada, foi produzido a partir de uma lasca cortical alongada de quartzito, claramente adequada ao fabrico de um utensílio com configuração bifacial. O outro biface é bilateralmente assi- métrico, evidencia extremidade distal também arredondada (com fracturas recentes) e foi produzido sobre um seixo rolado de quartzito de secção trapezoidal (morfologia esta igualmente adequada à confecção deste tipo de artefacto) (Fig. 15).

Relativamente ao machado de mão importa referir que se trata efetivamente de uma peça muito atípica (e até algo duvidosa), com silhueta em U, produzida sobre calote de seixo. O gume ativo 


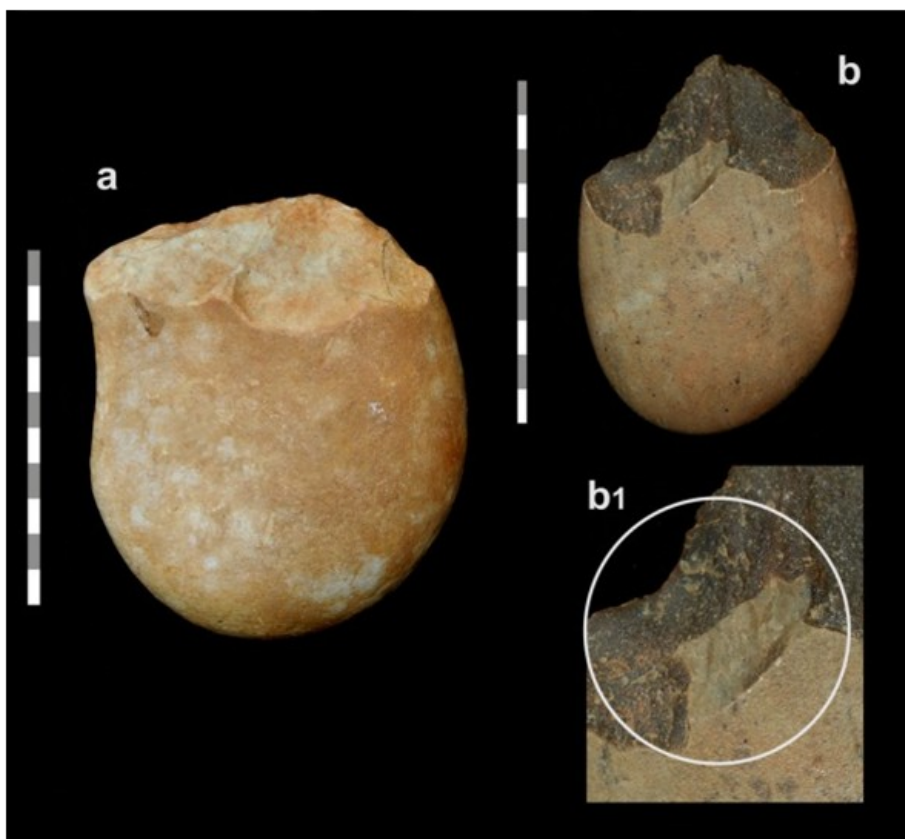

Fig. 15. A: Seixo talhado unifacial boleado e muito eolizado, possivelmente correlativo do depósito marinho do nível II. B: Seixo talhado unifacial de gume convergente. B1: Dupla pátina: observe-se um resquício de negativo intensamente eolizado recortado por negativos subsequentes sem vestígios de deflação.

Fig. 15. A: Rolled and aeolised chopper, possibly correlated with the / correlative of the marine deposit of level II. B: Chopper with convergent edges. B1: Double patina: note the remnant of an aeolised negative truncated by subsequent flaking.

resulta da interseção do plano da diáclase com o plano definido por um negativo inscrito na face oposta. As zonas de preensão coincidem com o dorso cortical que se estende desde o bordo direito da peça ao bordo esquerdo, passando pela região proximal. Este esboço de machado de mão, juntamente com os dois bifaces, evidenciam, como acima se referiu, rolamento nítido, pelo que se relacionarão com o depósito marinho.

Os seixos talhados constituem um conjunto de artefactos pouco expressivo, sobretudo no que diz respeito aos bifaciais (2). Os unifaciais estão documentados por 22 exemplares, sendo maioritários os de gume simples. Entre eles identificou-se um exemplar francamente boleado e com eolização, que embora recolhido numa coluvião (MAD1) poderá ser também correlativo do contexto marinho (Fig. 15). Uma outra peça, com gume convergente, proveniente de um depósito coluvionar de Valadares (PiscVAL), possui uma série de negativos "frescos" que recortam uma superfície onde ainda é visível parte de um negativo intensamente eolizado (Fig. 15), confirmado assim a existência de "dois momentos" de talhe distintos, temporalmente afastados.

Compostos exclusivamente por raspadores (com retoque inverso) (4), entalhes (2) e 1 denticulado, os utensílios sobre lasca estão igualmente mal representados. Em todo o caso deve salientar-se que esta situação poderá decorrer unicamente de aspectos relacionados com a fraca conservação dos contextos arqueológicos e não com opções tecno-culturais do Homem pré-histórico.
Por último, refiram-se os "diversos" (4) entre os quais se encontra um raspador sobre seixo, um raspador sobre calote de seixo e uma calote de seixo com prováveis retoques de utilização. Trata-se de artefactos que resultam claramente do aproveitamento expedito de suportes com uma morfologia naturalmente favorável à sua utilização como utensílios.

\subsection{Nível marinho III - Estação paleolítica da praia da Aguda}

Como acima se referiu, as peças líticas da estação paleolítica da Praia da Aguda (MONTEIRORODRIGUES \& GONZÁLEZ 2010), num total de 156 exemplares (Quadro 5), provêm da base de um depósito marinho implantado a cerca de $1 \mathrm{~m}$ a.n.m.a.m., conservado em áreas rebaixadas da actual plataforma de abrasão. De acordo com ARAúJo (2008) e ARAÚJO et al. (2003), este depósito poderá datar do Éemiano (c. 130-110 Ka).

As referidas peças constituem uma colecção francamente homogénea, não só em função das características técnicas e tipológicas que exibem, como também pelo facto de terem sido produzidas na sua quase totalidade a partir de quartzo leitoso com origem nos filões das rochas metamórficas locais (128 exemplares). Talhadas sobre seixo rolado de quartzito conhecem-se unicamente 28 , sendo que apenas 5 surgiram no depósito marinho. As restantes foram detectadas à superfície e incluem seixos talhados (7), percutores (4, um dos quais com vestígios de 
polimento) e "pesos de rede" (2), com estados físicos diferenciados. Exclui-se qualquer possibilidade de estes objectos se integrarem no conjunto principal proveniente do conglomerado marinho.

Ao que tudo indica, os artefactos líticos da Praia da Aguda terão sido produzidos num período em que o nível do oceano se encontrava mais baixo que o atual. No entanto, a disponibilidade de seixos rolados e de placas de quartzo com algum boleamento na área da estação arqueológica sugere que o local teria já sido, ou estaria a ser trabalhado pelo mar. A total ausência de rolamento nos materiais arqueológicos indicia o seu "rápido" enterramento, muito possivelmente na sequência da transgressão marinha responsável pela génese do nível III.

Uma vez que um estudo preliminar desta colecção foi já divulgado (MONTEIRO-RODRIGUES \& GONZÁLEZ 2010), assinala-se apenas a presença de bifaces e de machados de mão, o que permite relacionar esta indústria com o tecno-complexo Acheulense. Assinala-se também a ocorrência de núcleos explorados através de sequências de debitagem algo complexas como é o caso da Levallois recorrente centrípeta. Relativamente aos machados de mão, a sua produção decorreu da presença de grandes seixos rolados de quartzo susceptíveis de fornecer suportes adequados à sua confeção (Fig. 16).

Por outro lado, não se descarta a possibilidade da existência no local de uma indústria mais recente, eventualmente holocénica, documentada pelos seixos talhados de quartzito, pelos percutores e pelos "pesos de rede" a que acima se aludiu.

\section{CONCLUSÕES}

Não obstante a enorme dificuldade em precisar o posicionamento estratigráfico dos materiais líticos do litoral de Vila Nova de Gaia, é possível tecer algumas considerações de carácter geral relativamente aos seus contextos geoarqueológicos. Tais considerações, mais do que se assumirem como certezas, devem ser lidas fundamentalmente como linhas de investigação futura.

Os dados de que se dispõe atualmente sugerem a existência de indústrias líticas talhadas, ainda que raras, nos depósitos marinhos dos três níveis identificados em Gaia - nível I, nível II e nível III (ARAÚJO 1991). A ocorrência de bifaces em todos eles permite atribuir as referidas indústrias a diferentes fases do Acheulense.

No sítio do Cerro, a formação marinha do nível I foi ravinada por uma massa coluvionar denominada C4 ("coluvião antiga") (MONTEIRORODRIGUES \& CUNHA-RIBEIRO 1991, 2014), aparentemente também presente noutros pontos do litoral. Uma vez que na coluvião do Cerro abundam artefactos acheulenses, importa determinar, futuramente, se estes artefactos são efectivamente correlativos da coluvião ou se, pelo contrário, foram retomados da formação marinha basal no decurso do ravinamento. O aspecto "fresco" que as peças líticas apresentam e o facto de algumas delas terem sido detectadas em depressões do bedrock, onde poderão estar in situ, permitem ligá-las, provisoriamente, ao contexto marinho.

Os depósitos do nível II, com a exceção do depósito da praia das Pedras Amarelas, Lavadores (RIBEIRO et al. 2010; ARAÚJO 2008), encontram-se muito arrasados, surgindo no seu lugar formações coluvionares de espessura muito variável, que embalam os artefactos líticos talhados. $\mathrm{O}$ intenso boleamento evidenciado por alguns destes artefactos indica que se encontram em posição secundária, podendo, portanto, relacionar-se com o depósito marinho original.

De acordo com RIBEIRO et al. (2010), esta formação marinha data de $180 \pm 25 \mathrm{Ka}$ (OSL sobre quartzo). No entanto, considera-se que este valor poderá estar aquém da idade real do depósito uma vez que se aproxima do limite cronométrico possibilitado pela datação daquele mineral (CUNHA et al. 2008; MARTINS et al. 2009). Em todo o caso, este resultado confirma a idade plistocénica dos

Quadro 5. Distribuição quantitativa das diversas categorias de materiais

líticos recolhidos no depósito marinho do nível III (Praia da Aguda).

Table 5. Quantitative distribution of the different categories of lithics found in the marine deposit of level III (Praia da Aguda).

\begin{tabular}{|c|c|}
\hline & Praia da Aguda Q4b \\
\hline Núcleos & 53 \\
\hline Lascas & 49 \\
\hline Bifaces & 2 \\
\hline Machado de mão & 2 \\
\hline Seixos talhados & 12 \\
\hline Utensílios sobre lasca & 4 \\
\hline Pesos de rede & 2 \\
\hline Utensílios diversos & 2 \\
\hline Percutores & 4 \\
\hline Inclassificáveis & 26 \\
\hline Total & 156 \\
\hline
\end{tabular}




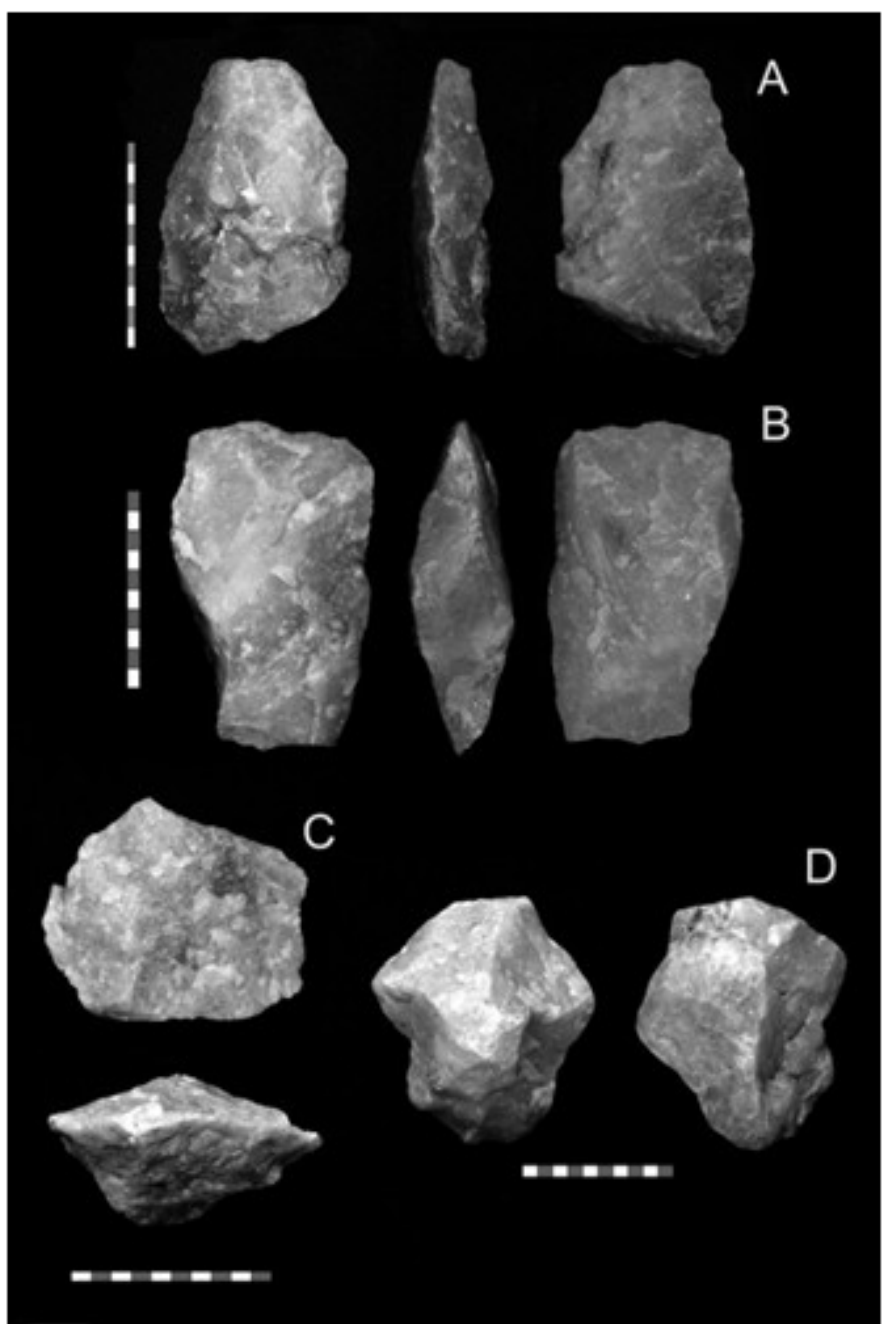

Fig. 16. Artefactos líticos em quartzo recolhidos na Praia da Aguda, no depósito marinho do nível III. A: Biface. B: Machado de mão. C: Núcleo levallois recorrente centrípeto. D: Núcleo com debitagem centrípeta bifacial.

Fig. 16. Lithics made of quartz found in Praia da Aguda, in the marine deposit of level III. A: Handaxe. B: Cleaver. C: Levallois recurrent centripetal core. D: Core with centripetal bifacial debitage.

depósitos do nível II e permite inferir a maior antiguidade do nível marinho I, que será necessariamente anterior ao MIS 6.

A formação marinha do nível III encontra-se bem documentada em vários pontos do litoral gaiense, nomeadamente nas praias de Salgueiros, Madalena e Aguda. Os seus melhores testemunhos são visíveis apenas durante a baixa-mar, normalmente após significativa remoção de areia provocada pelas marés-vivas e pelas tempestades.

O depósito da Praia da Aguda foi o único, até ao momento, que forneceu um conjunto expressivo de materiais líticos talhados. Como se referiu, estes artefactos constituem uma coleção técnica e tipologicamente homogénea, relacionando-se com a exploração do quartzo proveniente dos filões encaixados nos migmatitos da área. A confirmar-se a idade éemiana da formação marinha (e.g. ARAÚJO 2008), esta indústria poderá representar uma fase final do Acheulense regional (anterior a $\approx 130$ $\mathrm{Ka}$ ), aproximando-se eventualmente da transição para o Paleolítico Médio.

Nas coluviões que recobrem os níveis marinhos I e II, sobretudo nas do nível II, surgem outros artefactos eolizados a fortemente eolizados e sem boleamento, ao que tudo indica posteriores à génese das formações marinhas. Entre eles destacam-se alguns núcleos com estratégias de debitagem centrípeta, eventualmente testemunhos de etapas cronológico-culturais posteriores ao Paleolítico inferior ${ }^{2}$.

A referida eolização, reconhecida desde há

\footnotetext{
${ }^{2}$ A recente descoberta de um artefacto fraturado que parece ser um biface (não contemplado neste estudo), com ténue eolização e sem rolamento, coloca possibilidade de existirem também nestas formações coluvionares materiais acheulenses posteriores à génese do depósito marinho do nível II
} 
muito na Faixa Ocidental Meso-cenozóica, parece ter sido um fenómeno recorrente no decurso do Plistocénico (e.g. CARVAlHo 1950, 1953, 1954, 1964; DAVEAU 1980; GRANJA et. al. 2008; ANDRÉ et al. 2009). No litoral norte, ela manifestou-se de forma intensa há cerca de $85 \mathrm{Ka}(84 /+18-12 \mathrm{Ka})$, de acordo com uma datação obtida por TL no depósito eólico de São Paio (Vila do Conde), que se sobrepõe ao nível marinho III (Éemiano) (ARAÚJO 2008). Segundo Araújo, esta deflação é anterior à génese das principais coluviões identificadas neste setor costeiro uma vez que a "'formação areno-pelítica de cobertura' contém areia eólica e seixos muito eolizados na sua base (...)" (ARAúJo 1991: 353, 1995). Efectivamente, num depósito coluvionar de Lavadores (V. N. de Gaia), relacionado com a referida formação, obteve-se uma datação pelo radiocarbono em torno de $45 \mathrm{Ka}$ BP (idade mínima) (idem).

Em alguns locais recentemente visitados pelos autores deste texto, nomeadamente em Valadares e na Madalena (V. N. de Gaia), identificouse, sobre os níveis marinhos I e II, uma cobertura sedimentar essencialmente siltosa, que poderá corresponder a um depósito loéssico, de idade para já indeterminável, que remete igualmente para ambientes com forte deflação.

Estudos realizados em formações dunares do sudoeste de França, relacionáveis com formações do mesmo tipo existentes no litoral português (SITZIA et al. 2015), permitiram reconhecer diversas fases de eolização plistocénica, remontando as mais antigas pelo menos ao MIS 10. Durante o último glaciar essas fases foram recorrentes, encontrando-se datadas de 64-42 ka, 24-14 ka, do Dryas III e do Holocénico (séc. XI-XVIII AD) (SITZIA et al. 2015; BERTRAN et al. 2009).

Para além dos referidos artefactos líticos eolizados recolheram-se também, nas formações coluvionares, peças sem qualquer alteração física, que poderão ser contemporâneas da génese destes depósitos, remontando, genericamente, ao Plistocénico superior. Outras, porém, ainda que com o mesmo estado físico, evidenciam características técnicas e tipológicas que permitem atribuir-lhes uma idade holocénica. De referir, a título de exemplo, o caso das peças em sílex, em quartzo fumado e os pesos de rede. No sítio das Areias Altas (Porto), pesos de rede semelhantes aos recolhidos no litoral de Vila Nova de Gaia foram recentemente datados da Idade do Bronze (Sac-2474: $3820 \pm 45$ BP; Sac-2475: 3800 \pm 50 BP) (LUZ 2010).

Por último, importa referir que a compreensão da realidade arqueológica a que aqui se alude só poderá processar-se mediante o estudo multidisciplinar dos depósitos que na região ainda se conservam, tendo como principais objectivos o aumento da amostragem de artefactos líticos, a determinação dos seus contextos estratigráficos e, se possível, a aferição da cronologia absoluta das formações sedimentares.

\section{BIBLIOGRAFIA}

ANDré, J.N.; CUnHA, P.P.; DinIS, J.; Dinis, P.; CORDEIRO, F. 2009. Características geomorfológicas e interpretação da evolução do campo dunar eólico na zona costeira entre a Figueira da Foz e a Nazaré. Publicações da Associação Portuguesa de Geomorfólogos (APGEOM), VI: 39-44

ARAÚJo M.A. 1991. Evolução geomorfológica da plataforma litoral da região do Porto. Dissertação de Doutoramento, Universidade do Porto. Disponível em: http://web.letras.up.pt/asaraujo/Trabalhos/09\% 20 tese $\% 20$ com $\% 20$ fotos $\% 20$ protegida.pdf

ARAÚJo M.A. 1995. Os fácies dos depósitos würmianos e holocénicos e as variações climáticas correlativas na plataforma litoral da região do Porto. Actas do VI Colóquio Ibérico de Geografia, Vol. II, Porto, Universidade do Porto: 783-793.

ARAúJo M.A. 2008. Depósitos do Pleistocénico Superior e do Holocénico na plataforma litoral da região do Porto: a morfologia das plataformas de erosão marinha e a tectónica recente. Estudos do Quaternário 5: 17-30.

AraúJo M.A.; Gomes, A.; Chaminé, H.I.; FonsecA, P.E.; Gama Pereira, .L.C. \& Jesus, J.P. 2003. Geomorfologia e geologia regional do sector de PortoEspinho (W de Portugal): implicações morfoestruturais na cobertura sedimentar cenozóica. Cadernos do Laboratorio Xeológico de Laxe 28: 79-105.

Bertran, P.; Allenet, G.; Gé, Th.; Naughton, F.; POIRIER, PH.; SANCHEZ GOÑI, M.F. 2009. Coversand and Pleistocene palaeosols in the Landes region, southwestern France. Journal of Quaternary Science, 24(3): 259-269. DOI: 10.1002/jqs. 1220

BRANDÃO, D.P. 1962. Novos elementos arqueológicos de Lavadores - Gaia. Breve nótula. Lucerna, II (1-2) 79-81.

CABRAL, F.A.V.P. 1881. Estudo de depositos superficiaes da Bacia do Douro. Lisboa, Secção dos Trabalhos Geologicos de Portugal.

CARvalho, G.S. de 1950. Contribuição para a interpretação da origem dos depósitos Plio-plistocénicos da Orla Meso-cenozóica ocidental (região entre o Vouga e o Mondego). Mem. Not. Mus. Lab. Min. Geol. Univ. Coimbra, Vol. 28: 26-48.

Carvalho, G.S. de 1953. Les époques d'éolisation du Pleistocène dans la Bordure Occidentale Mésocenozoïque du Portugal. Separata da Revista da Faculdade de Ciências da Universidade de Coimbra, Vol. XXII: 5-10.

Carvalho, G.S. de 1954. A Gândra (Portugal) e as landes da Gasconha (França). Mem. Not. Mus. Lab. Min Geol. Univ. Coimbra, Vol. 37: 3-19.

Carvalho, G.S. de 1964. Areias da Gândra (Portugal); uma formação eólica quaternária. Publ. Mus. Lab. Min Geol. Fac. Ciências, Vol. 82, 4ª́rie: 7-32.

CORTEZ, F.R. 1946. Estaciones paleoliticas de los alredores de Oporto (Lavadores, Pasteleira). Archivo Español de Arqueologia, 64: 249-257.

Cunha, P.P.; Martins, A.A.; Huot, S.; Murray, A.; RAPOSO, L. 2008. Dating the Tejo river lower terraces in the Ródão area (Portugal) to assess the role of tectonics and uplift. Geomorphology, doi:10.1016/j.geomorph.2007.05.019 
CunHA-Ribeiro, J.P. 1999. O Acheulense no Centro de Portugal: $O$ vale do Lis. Contribuição para uma abordagem tecno-tipológica das suas indústrias líticas e problemática do seu contexto cronoestratigráfico. Dissertação de Doutoramento, Universidade de Lisboa. Policopiado.

Cunha-Ribeiro, J.P.; Monteiro-Rodrigues, S. \& MascaRENHAS, A.M. 1990. Hachereaux e Seixos Talhados: Significado da sua presença nas Indústrias Acheulenses no Centro de Portugal. II Colóquio Arqueológico de Viseu. Livro do Colóquio (26-29 de Abril de 1990), Viseu, Associação de Defesa do Património e Ambiente e Amigos da Beira: 42.

FONTES, J. 1916. Instruments paléolitithiques dans la collection de Préhistoire du Service Géologique. 2 Instruments paléolithiques des environs de Porto. Extrait des Comunicações do Serviço Geológico de Portugal, 12: 1-5.

DaveaU, S. 1980. Espaço e Tempo. Evolução do ambiente geográfico de Portugal ao longo dos tempos préhistóricos. Clio, 2: 13-37.

Gomes, A.; ARaúJo, M.A. 2005. The Littoral of Oporto Region (NorthWest Portugal). In Field Trip Guide of Portugal Coastal Dynamics. Sixth International Conference on Geomorphology, Field Trip Guide A1 (7-11 September 2005), Zaragoza, International Association of Geomorphology, p. 7-10

Granja, H.M., DE Groot, T.A.M.; Costa, A.L. 2008. Evidence for Pleistocene wet aeolian dune and interdune accumulation, S. Pedro da Maceda, NortheWest Portugal. Sedimentology, 55: 1203 1226.

LuZ, S. 2010. O depósito de conchas do sítio arqueológico das Areias Altas (Porto, Portugal). Discussão do enquadramento arqueológico da estrutura 15. Férvedes, 6 (I Reunión Científica de Arqueomalacología de la Península Ibérica, León, 20-21 de mayo de 2010): 141-145.

Martins, A.A.; Cunha, P.P.; HuOt, S.; Murray, A.S.; BUYLAERT, J.P. 2009. Geomorphological correlation of the tectonically displaced Tejo River terraces (Gavião - Chamusca area, central Portugal) supported by luminescence dating. Quaternary International 199: 75-91. doi:10.1016/j.quaint.2009.01.009

MeIRELes, J. 1992. As Indústrias Liticas Pré-históricas do Litoral Minhoto. Contexto Cronoestratigráfico e Paleoambiental. Braga, UAUM e CCHS (Cadernos de Arqueologia - Monografias).

MeIreles, J. 2009. Os Primeiros Povoadores. A Pré-história Antiga do Minho. In: Minho. Traços de Identidade, Braga, Universidade do Minho: 20-66.

Monteiro-Rodrigues, S. 2000. A Pré-história Antiga da região do Porto: Síntese bibliográfica. Al-madan, II série, 9: 74-78.

Monteiro-Rodrigues, S. 2013. Estação paleolítica do Cerro, Madalena, Vila Nova de Gaia. In: Ana M.S. BETTENCOURT, A Pré-História do Noroeste Português. L. Oosterbeek (Dir.), Territórios da PréHistória em Portugal, Vol. 2, Braga-Tomar, CEIPHAR e CITCEM (Arkeos, 36): 103-107.
Monteiro-Rodrigues, S. \& CunHA-RiBeiro, J.P. 1991. A Estação Paleolítica do Cerro (Madalena, Vila Nova de Gaia). Revista da Faculdade de Letras - História, II série, 8: 411-428.

Monteiro-Rodrigues, S. \& Cunha-Ribeiro, J.P. 2014. A Estação Paleolítica do Cerro (Vila Nova de Gaia, Noroeste de Portugal): Caracterização preliminar dos utensílios com configuração bifacial. Estudos do Quaternário 11: 3-18. http://www.apeq.pt/ojs/ index.php/apeq.

Monteiro-Rodrigues, S. \& GonzÁlez, A. 2010. A estação paleolítica da Praia da Aguda (Arcozelo, Vila Nova de Gaia). Notícia preliminar. Estudos do Quaternário, 6: 23-36.

Monteiro-Rodrigues, S. \& SAnCheS, M.J. 2006. Os primeiros recolectores e caçadores (Paleolítico). In C.A. Brochado de Almeida (Coord.), História do Douro e do Vinho do Porto. História Antiga da Região Duriense, Vol. I, Porto, GEHVID e Ed. Afrontamento: 30-77.

Oliveira, J. T., Pereira, E., Ramalho, M., Antunes, M T.; Monteiro, J. H. [Coords.] (1992). Carta Geológica de Portugal à escala 1/500 000. Lisboa, Serviços Geológicos Portugal

PINTO, R.S. 1927. Introdução à arqueologia portuense. $O$ Tripeiro, $3^{\mathrm{a}}$ série, 2(26) (Janeiro): 24-25.

Ribeiro, H.; De Jesus, A.P.; Mosquera, D.F.; Abreu, I.; VIDAL ROMANI, J.R. \& NORONHA, F. 2010. Estudo de um terraço de Lavadores. Contribuição para a dedução das condições paleoclimáticas no Plistocénico médio. e-Terra. Revista Electrónica de Ciências da Terra, Vol. 21/1: 1-4. http://eterra.geopor.pt

SANTONJA, M. 1984-1985. Los núcleos de lascas en las industrias paleolíticas de la meseta española, Zephyrvs, 37-38: 17-33.

Sitzia, L.; Bertran, P.; BAHAIN, J.J.; BATEMAN, M.D.; HernandeZ, M.; Garon, H.; DE LAfontaine, G.; Mercier, N.; Leroyer, Ch.; QuefFEleC, A.; VOINCHET, P. 2015. The Quaternary coversands of southwest France. Quaternary Science Reviews, 124: 84-105.

Teixeira, C.; Perdigão, J.; Assunção, C. T. (1962). Carta Geológica de Portugal à escala de 1/50000. Notícia explicativa da folha 13-A (Espinho). Lisboa, Serviços Geológicos de Portugal

TIXIER, J. 1956. Le hachereau dans l'Acheuléen nordafricain. Notes typologiques. In: Congrès préhistorique de France, $X V^{\text {eme }}$ Session (PoitiersAngoulême, 15-22 Juillet 1956): 914-923.

ZBYsZewsKI, G. 1943. La classification du Paléolithique ancien et la chronologie du Quaternaire du Portugal en 1942, Boletim da Sociedade Geológica de Portugal, vol. II (2-3): 1-113.

ZByszewski, G. 1957. Le Quaternaire du Portugal. Lisboa, Instituto de Alta Cultura. 